\title{
Custos de produção de artigos têxteis e Avaliação da possibilidade de terceirização da fabricação após a reorganização do arranjo físico
}

\begin{abstract}
Marcelo Aguiar Baptista Graduação em Engenharia de Produção na Universidade Católica de Petrópolis - UCP Rua Benjamin Constant. Petrópolis/RJ. CEP: 25610-130 E-mail:marcelo_zancanelli@hotmail.com
\end{abstract}

\begin{abstract}
Allan Jonathan da Silva Doutorado em andamento em modelagem computacional pelo Laboratório Nacional de Computação Científica Professor de Estatística e Pesquisa Operacional no Centro Federal de Educação Tecnológica Celso Suckow da Fonseca - CEFET/RJ Avenida Maracanã, 229. Maracanã. Rio de Janeiro/RJ. CEP: 20271-110 E-mail: allan.jonathan@gmail.com

Fabini Hoelz Bargas Alvarez Mestrado em Administração de Empresas pelo Instituto Brasileiro de Mercado de Capitais/RJ Coordenador do Curso de Engenharia de Produção pela Universidade Católica de Petrópolis - UCP Rua Barão do Amazonas, 124. Centro. Petrópolis/RJ. CEP: 25685-070 E-mail: fabini.alvarez@ucp.br
\end{abstract}

\section{RESUMO}

Com o crescimento da competitividade entre as empresas, é crucial que as decisões sejam amparadas por técnicas quantitativas. Quando se trata de encontrar alternativas para a redução do custo de produção de seus artigos, essas decisões podem impactar a sobrevivência da organização. Este trabalho desenvolve um estudo de técnicas de custeio e melhoria de processos aplicados a uma empresa do ramo têxtil. O objetivo é calcular o custo de produção interna de um certo produto e compará-lo com o preço da terceirização. Foram utilizados dados de produção dos anos 2013 e 2014, quando implementou-se diversas melhorias no processo de produção de um determinado artigo têxtil. Observou-se uma significativa redução no custo unitário do produto após melhorias no arranjo físico, utilizando-se o método de custeio $A B C$, e conclui-se que é viável economicamente produzir o artigo internamente.

Palavras-chave: Método de custeio ABC. Engenharia de Métodos. Terceirização.

Costs of textile items production and evaluation and the possibility of manufacturing outsourcing after the reorganization the layout 
Custos de produção de artigos têxteis e Avaliação da possibilidade de terceirização da fabricação após a reorganização do arranjo físico Marcelo Aguiar Baptista, Allan Jonathan da Silva, Fabini Hoelz Bargas Alvarez

\section{ABSTRACT}

With the growing competition among companies, it is crucial that decisions are supported by quantitative techniques. When concerned to find alternatives to reduce the cost of producing company's articles, these decisions can impact the organization's own survival. This paper develops a study related to costing techniques and to the improvement of processes applied to a textile company. The goal is to calculate the cost of domestic production of a certain product and compare it with the price of outsourcing.In the years 2013-2014, data related to production were used when various improvements have been implemented in the production process of a particular textile article. There was a significant reduction in the unit cost of the product, by use of the $\mathrm{ABC}$ costing method, and also was concluded that it is economically feasible to produce the article internally.

Keywords: Costing Method ABC. Methods Engineering. Outsourcing.

\section{INTRODUÇÃO}

Qualquer atividade industrial necessita de análise de viabilidade econômicofinanceira. No entanto, a avaliação da sustentabilidade de um negócio é bastante complexa, devido à quantidade de custos envolvidos em todos os processos. A correta alocação dos custos fixos e variáveis aos custos individuais dos produtos, a fim de encontrar o seu ponto de equilíbrio, não é uma tarefa simples. Para tratar deste tema, há uma vasta literatura sobre análise de custos, tanto do ponto de vista contábil (LIMEIRA, 2012) como do ponto de vista de custeio ((MARTINS, 2010) e (PINTO et al., 2011)).

Este trabalho estuda a aplicação prática de métodos que auxiliam na gestão e alocação dos custos, a fim de comparar os gastos relativos à terceirização da produção de artigos têxteis com a produção interna dos mesmos. Para isso, um estudo empírico foi realizado posteriormente a uma extensa pesquisa teórica sobre ferramentas de custeio, decisões sobre terceirização e engenharia de métodos. A partir desses resultados, são utilizadas ferramentas de engenharia com o objetivo de reduzir os custos internos, a fim de avaliar a substituição de toda a terceirização pela produção total na empresa. 
Custos de produção de artigos têxteis e Avaliação da possibilidade de terceirização da fabricação após a reorganização do arranjo físico Marcelo Aguiar Baptista, Allan Jonathan da Silva, Fabini Hoelz Bargas Alvarez

O objetivo do trabalho é a aplicação do método ABC (NAKAGAWA, 2001) na comparação dos custos de produção de artigos têxteis antes e depois de alterações no arranjo físico industrial para, então, avaliar a viabilidade financeira da atividade produtiva frente à terceirização dos produtos.

Para o estudo, foi realizado um levantamento de todos os custos internos e externos do produto, tendo como base o relatório de produção mensal de cada máquina e seu artigo produzido, assim como todas as despesas da empresa. Feito isso, comparam-se esses valores com o custo de facção do artigo numa empresa terceirizada.

Atualmente, a empresa possui um maquinário que produz aproximadamente 25 toneladas de malhas/mês. Porém, nos meses de alta no mercado, essa quantidade não é suficiente para atender seu distribuidor. Nesses casos, a empresa precisa recorrer a grandes empresas que fazem facção de tecelagem do artigo têxtil, ou seja, a empresa compra o fio de um fornecedor e entrega direto na empresa que vai realizar a facção. Havendo a possibilidade de produção interna desses artigos que possuem terceirização, onde há a geração de mais despesas, em conjunto com a maximização da produção e o desenvolvimento de meios para deferir certo nível de qualidade e excelência para a produção, seria mais viável trazer a produção toda para a pequena empresa, regulando as despesas dos períodos para que não haja prejuízo financeiro e contábil.

Em conjunto com essa dificuldade em aumentar a capacidade de produção sem aumentar o maquinário, há o aumento das despesas do período, que passam a ir além dos custos de produção (luz, telefone, salários, matéria prima, entre outros). Por esta razão, passa-se a englobar os custos da produção realizada por terceiros, em que o mesmo pode ser inúmeras vezes superior ao seu custo, produzindo o mesmo artigo. $\mathrm{E}$ ainda tem-se como objetivo reduzir os custos do período, pela não utilização dos serviços de terceiros para a produção de artigos, dos quais a empresa detém a capacidade de produzir, além de maximizar a produção juntamente com a melhora da qualidade do artigo produzido. 
Custos de produção de artigos têxteis e Avaliação da possibilidade de terceirização da fabricação após a reorganização do arranjo físico Marcelo Aguiar Baptista, Allan Jonathan da Silva, Fabini Hoelz Bargas Alvarez

Mediante a redução dos custos de produção, ou manutenção para o aumento da produção, haverá o aumento do lucro, o qual permitirá uma melhora na qualidade e, possivelmente, expansão da empresa em termos de aquisição de maquinário para ampliar a capacidade de produção, sem que haja algum gargalo por conta da falta de estrutura e maquinário.

Devido à crise em que o país se encontra, a empresa também necessita de um controle de custos mais apurado a fim de determinar, com maior precisão, os preços de venda dos produtos, face ao aumento da concorrência.

A ideia para solução do problema é a aplicação do método $A B C$, baseado em atividades, sendo o método mais preciso de custeio. Conceitualmente, o método $A B C$ é uma metodologia desenvolvida para facilitar a análise estratégica de custos relacionados com as atividades que mais impactam o consumo de recursos de uma empresa.

Este trabalho apresentará a empresa objeto de estudo, o histórico dos seus custos, sob a ótica do $\mathrm{ABC}$, antes e depois da reorganização do arranjo físico e dos resultados da aplicação dos métodos de engenharia na empresa.

\section{ESTUDO DE CASO}

\subsection{Escolha do objeto de estudo e metodologia}

O objetivo central deste trabalho é a análise dos custos de produção internos e externos de artigos têxteis. Para isso, é utilizada a aplicação do método de custeio por Atividades $(A B C)$ numa empresa do ramo Têxtil.

A empresa escolhida chama-se MF Têxtil. Essa empresa realiza a facção de malhas diversas para atender o grupo de empresas ao qual ela pertence. Basicamente, o grupo compra a matéria-prima (fio) e a envia para a MF. Esta empresa possui oito teares circulares elétricos que produzem seus artigos têxteis. Esses artigos são enviados para uma tinturaria localizada no estado de Santa Catarina, para o processo de tintura e lavagem. Após todo o processo, os artigos são enviados novamente para 
Custos de produção de artigos têxteis e Avaliação da possibilidade de terceirização da fabricação após a reorganização do arranjo físico Marcelo Aguiar Baptista, Allan Jonathan da Silva, Fabini Hoelz Bargas Alvarez

Petrópolis, onde está situada a matriz do grupo, e enviados para seus dois pontos de venda: - um no município de Petrópolis e o outro no município do Rio de Janeiro.

O grupo passou a praticar a terceirização no ano de 2010, devido ao crescente aumento das vendas no mercado de malhas, pois sua capacidade de produção não atendia a demanda. Com isso, além de sua produção interna, passou a contar com a produção externa. A empresa passou a comprar a matéria-prima e a enviar diretamentepara Santa Catarina, pois a mesma empresa que tinge seus produtos também oferece o serviço de tecelagem da malha.

A grande questão levantada reside na análise de custos, a fim de verificar o que é mais vantajoso para a empresa:

- Continuar produzindo em sua própria fábrica, tendo que enviar seu produto acabado para a tinturaria e mantendo todos os seus custos fixos e variáveis para fabricar o artigo;

- Ou fechar a sede da empresa, e passar a fabricar e tingir toda a sua produção em Jaraguá do Sul.

O custo de produção na empresa terceirizada, em Santa Catarina, de $1 \mathrm{~kg}$ do artigo Meia Malha que será estudado no trabalho é de $R \$ 1,00$. Por meio do método de Custeio $A B C$, será calculado o custo de produção do mesmo artigo realizado na empresa MF Têxtil em Petrópolis.

As vantagens de terceirizar o artigo diretamente junto à empresa localizada em Santa Catarina são:

- Dispor do galpão onde funciona a empresa;

- Cortar os gastos com folha de pagamento e contabilidade;

- Conseguir dar mais atenção aos pontos de venda, focando mais em distribuição.

As desvantagens dessa atividade são:

- Não se sabe ao certo se a empresa terceirizada está realmente utilizando a matéria prima que foi enviada pelo grupo, pois o produto, depois de tinto, dificulta a identificação da matéria prima utilizada, devido à complexidade nas tramas de malha. Dessa forma, se forem utilizadas matérias primas diferentes na confecção 
Custos de produção de artigos têxteis e Avaliação da possibilidade de terceirização da fabricação após a reorganização do arranjo físico Marcelo Aguiar Baptista, Allan Jonathan da Silva, Fabini Hoelz Bargas Alvarez

da malha, ocorrerão diversos problemas que só poderão ser diagnosticados com o consumidor final (cliente), o que acarreta perda de credibilidade no mercado.

- A quantidade de matéria prima comprada nunca é igual à quantidade do produto final. Verifica-se uma "quebra", termo utilizado no ramo têxtil, para identificar o percentual de matéria prima desperdiçado no ar e nos processos de tintura. Toda carga de matéria prima enviada para faç̧ão é de, aproximadamente, 20 Toneladas/Mês. Como há pressa para que o produto final chegue ao ponto de venda, a facção envia mercadoria fracionada em entregas semanais, dificultando assim o controle.

- Diversas empresas concorrentes enviam matéria prima para essa empresa terceirizada. Logo, em épocas de grande demanda do mercado, a mercadoria atrasa, em média, três semanas para chegar ao ponto de venda, causando prejuízo ao grupo.

O estudo empírico abaixo foi realizado a partir de um levantamento de dados dos anos 2013 e 2014. Durante o período de 2014, foram realizadas diversas melhorias.

\subsection{A empresa}

Fundada no ano de 1994, a MF Têxtil iniciou suas atividades para atender a produção de artigos têxteis de um grupo empresarial localizado em Petrópolis. Suas instalações iniciais estavam localizadas na rua Teresa, forte ponto de comércio de vestuário da cidade. A fábrica ficava localizada num prédio de $350 \mathrm{~m}^{2}$, no $2^{\circ}$ andar de um ponto de venda utilizado pela empresa.

Em 2009, mudou-se para um galpão de $1500 \mathrm{~m}^{2}$, no bairro Cascatinha, na mesma cidade, contando com uma moderna infraestrutura. Possui duas lojas, que comercializam têxteis para venda a confeccionistas e revendedores, localizadas na rua Teresa, em Petrópolis, e outra no bairro do Rio Comprido, na cidade do Rio de Janeiro.

As atividades fabris da empresa estão situadasem Cascatinha, Petrópolis. Atualmente, tem uma capacidade de produção de 25 toneladas/mês. Conta com o serviço de facção terceirizado, onde realiza a compra de matéria prima e a envia diretamente para a empresa responsável por tecer e tingir os produtos. Além disso, 
Custos de produção de artigos têxteis e Avaliação da possibilidade de terceirização da fabricação após a reorganização do arranjo físico Marcelo Aguiar Baptista, Allan Jonathan da Silva, Fabini Hoelz Bargas Alvarez

revende produtos de diversos fornecedores, e toda essa mercadoria é distribuída em seus dois pontos de venda, tendo uma saída média mensal de 42 toneladas/mês.

Conta com nove colaboradores, sendo seis na produção e três na área administrativa. $\mathrm{Na}$ área de produção, possui quatro operadores de teares (tecelões), um auxiliar de produção e um funcionário responsável pela limpeza. A empresa opera de segunda a sexta-feira, das $07 \mathrm{~h} 00 \mathrm{~min}$ às $16 \mathrm{~h} 50 \mathrm{~min}$, respeitando 1 hora de almoço e mais 20 minutos de café. Durante esses horários, sua produção não pára, pois se utiliza do revezamento de funcionários. Dessa forma, pode-se considerar que todos os teares funcionam 10hs/dia. Na maior parte do ano, não se utilizam horas-extras, porém, quando há demanda de mercado, pode-se operar até as $18 \mathrm{~h}$ ou até as $21 \mathrm{~h}$, acrescentando horas extras aos funcionários. Atualmente, a produção é dividida em dois setores: Circulares e Retilíneas.

\subsubsection{Teares Circulares}

Teares Circulares são máquinas que possuem grande número de alimentadores, possibilitando maior produção e tecidos mais finos. Dentro desse tipo de máquinas, existem as monocilíndricas e as de dupla frontura. Máquinas Circulares monocilíndricas são máquinas com apenas uma frontura, chamada de cilindro, na posição vertical. Seu produto final é o tecido "Jersey" ou, como é conhecido mais popularmente, meia-malha. Máquinas Circulares de dupla frontura (Figura 1), como o próprio nome indica, são máquinas possuidoras de duas fronturas de agulhas denominadas cilindro (na posição vertical) e disco (na posição horizontal) e são máquinas próprias para a produção de malhas duplas. 
Custos de produção de artigos têxteis e Avaliação da possibilidade de terceirização da fabricação após a reorganização do arranjo físico Marcelo Aguiar Baptista, Allan Jonathan da Silva, Fabini Hoelz Bargas Alvarez

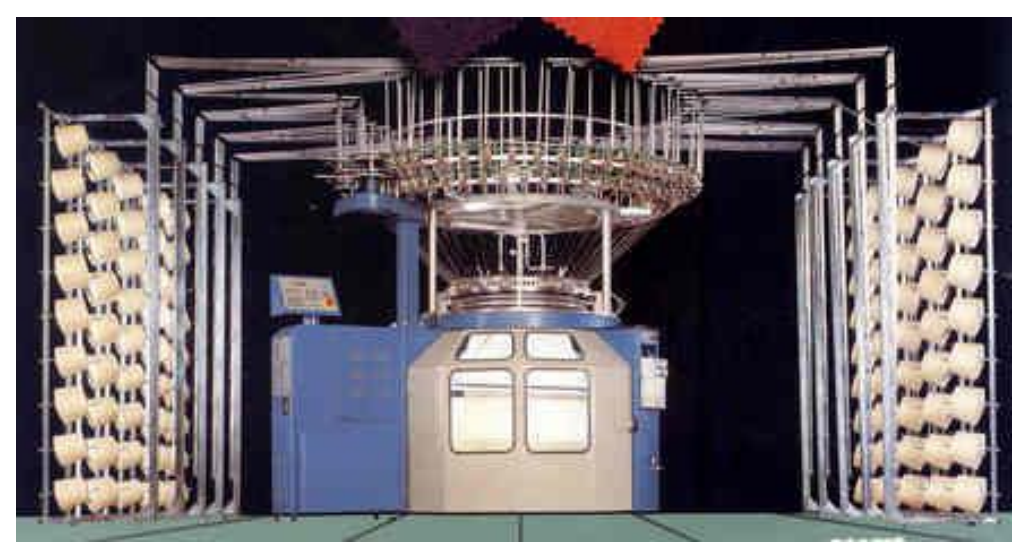

Figura 1 - Tear Circular

Fonte: Empresa

Os principais tecidos de malha por elas produzidos são o "Rib", o "Interlock" e o "Jacquard". A grande variedade de tecidos fabricados por este tipo de máquina encontra-se diretamente ligada às possibilidades de tecimento por elas apresentadas.

\subsubsection{Teares Retilíneos}

Teares retilíneos (Figura 2) fazem todos os tipos de tecidos de malha para vestuário, mas são também utilizados na fabricação de acabamentos, como golas e punhos para camisas de malha do tipo "polo" e tecidos com desenhos próprios para a produção de blusas e blusões. Bastante numerosos, são mais utilizados por pequenas empresas e confecções.

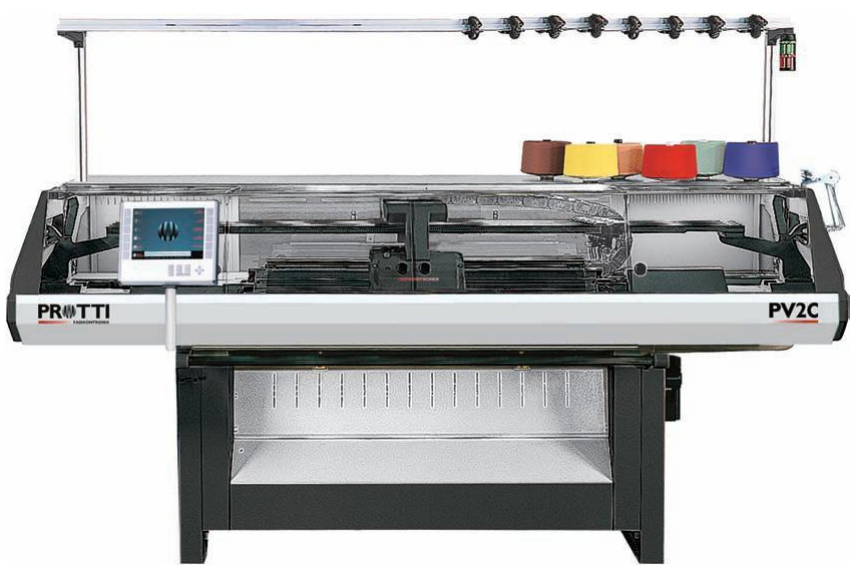

Figura 2 - Tear Retilíneo

Fonte: Empresa 
Custos de produção de artigos têxteis e Avaliação da possibilidade de terceirização da fabricação após a reorganização do arranjo físico Marcelo Aguiar Baptista, Allan Jonathan da Silva, Fabini Hoelz Bargas Alvarez

O setor circular é composto por oito teares elétricos, lubrificados a óleos. Para operar esses teares, são utilizados três tecelões e um auxiliar de produção, todos responsáveis por operar dois teares. Este auxiliar é responsável por retirar a matéria prima do estoque e alimentar os teares e retirar o produto acabado, encaminhando-o para a produção. A seção retilínea possui um tecelão responsável por operar os teares. A empresa é dividida em estoque, produção e expedição.

\subsection{Melhorias aplicadas}

\subsubsection{Layout Empregado}

Observando no layout da empresa, há uma área com déficit de aproveitamento, apresentando problemas em relação à operação dos tecelões pela distância percorrida, e pela falta de espaço para alimentação dos teares.

No layout observado (Figura 3), têm-se sete teares na parte circular superior e um tear naparte inferior, com uma distância média de 15 metros dos outros teares. Todos os teares possuem alimentação por gaiola lateral e forma de 'U'. Como cada tecelão precisa operar três teares, essa arrumação em ' $U$ ' dificulta sua visibilidade para observar outros teares, gerando muitas vezes atrasos na produção. O operador responsável pelos teares 7,8 e 9 tinha a pior produção dos três operadores, devido ao deslocamento de tear a tear. 
Custos de produção de artigos têxteis e Avaliação da possibilidade de terceirização da fabricação após a reorganização do arranjo físico Marcelo Aguiar Baptista, Allan Jonathan da Silva, Fabini Hoelz Bargas Alvarez

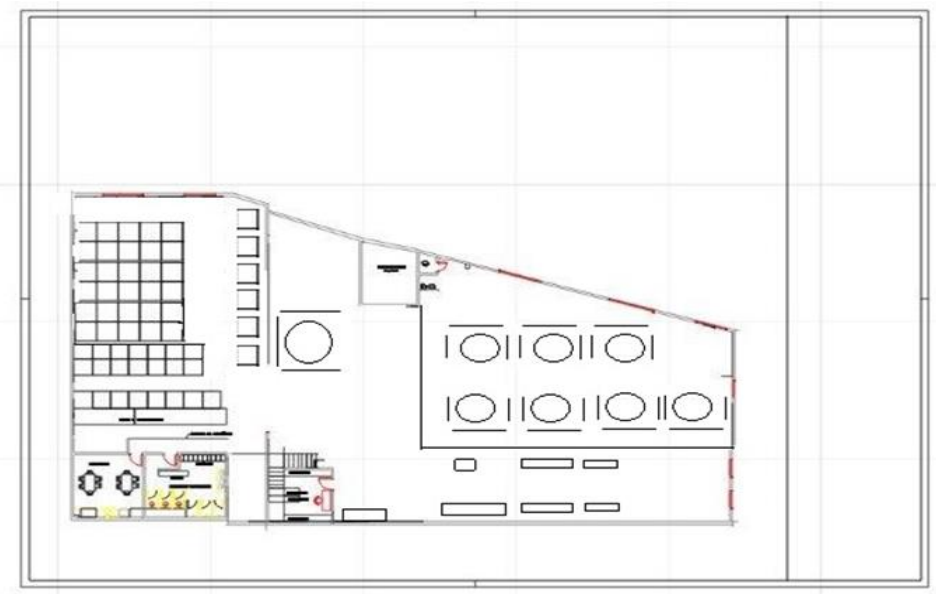

Figura 3 - Layout antigo

Fonte: Autor

A produção retilínea fica ao lado da produção circular e é prejudicada devido ao acúmulo de resíduos gerados pela produção circular. Em função disso, há uma divisão composta por barras de Metalon e vinil fazendo uma parede para separá-las. Mesmo com essa parede, esses resíduos caem sobre os teares retilíneos, fazendo uma mistura nos fios utilizados, causando defeitos no material acabado e parando os teares para manutenção.

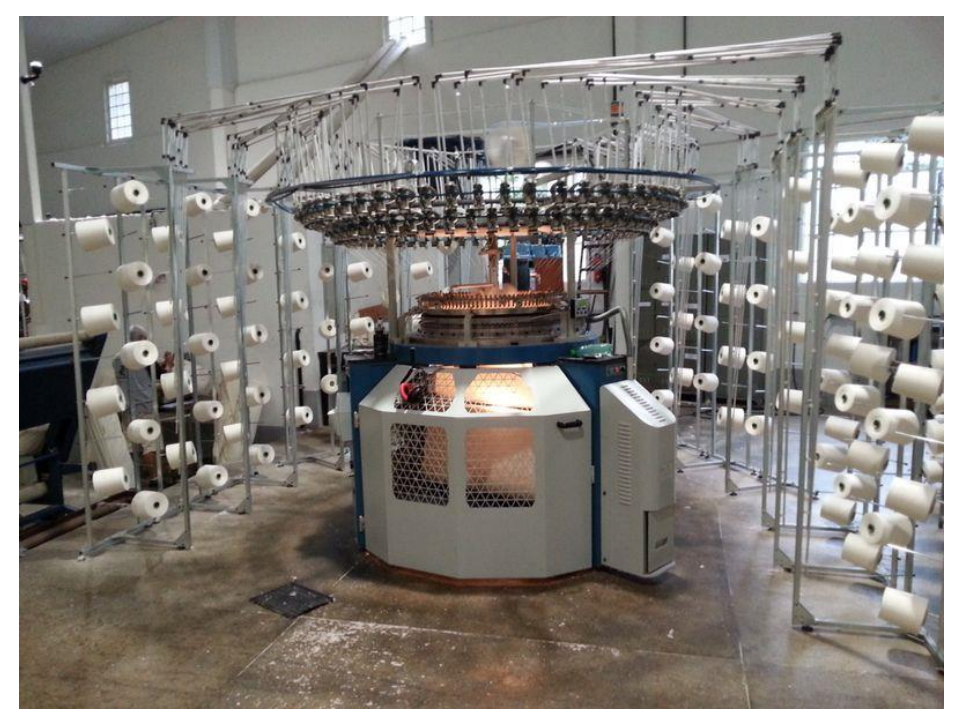

Figura 4 - Gaiolas de alimentação em 'U' Fonte: Empresa 
Custos de produção de artigos têxteis e Avaliação da possibilidade de terceirização da fabricação após a reorganização do arranjo físico Marcelo Aguiar Baptista, Allan Jonathan da Silva, Fabini Hoelz Bargas Alvarez

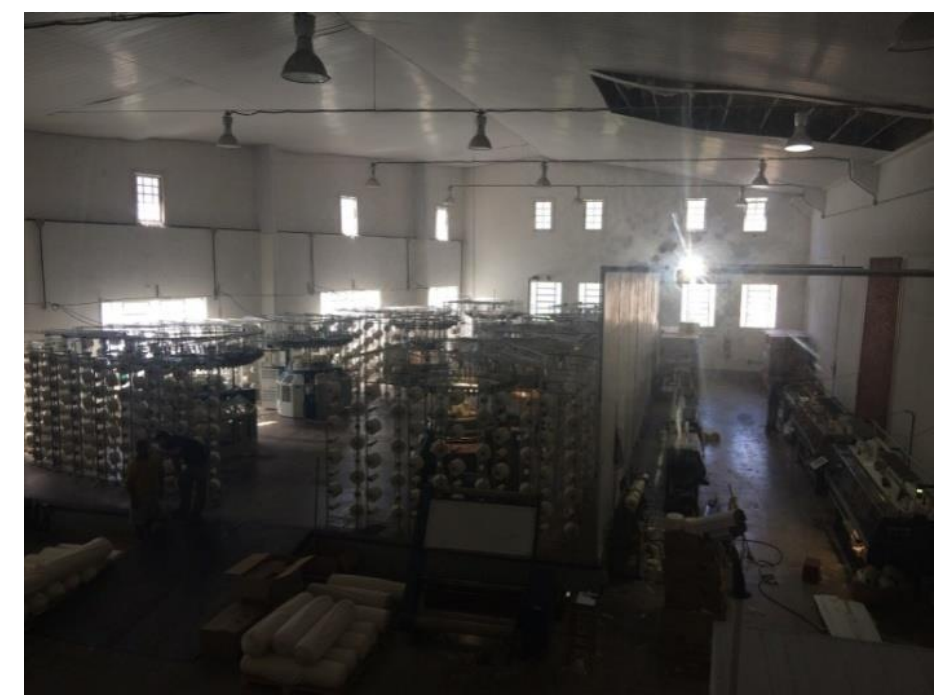

Figura 5 - Localização Seção Retilínea Fonte: Empresa

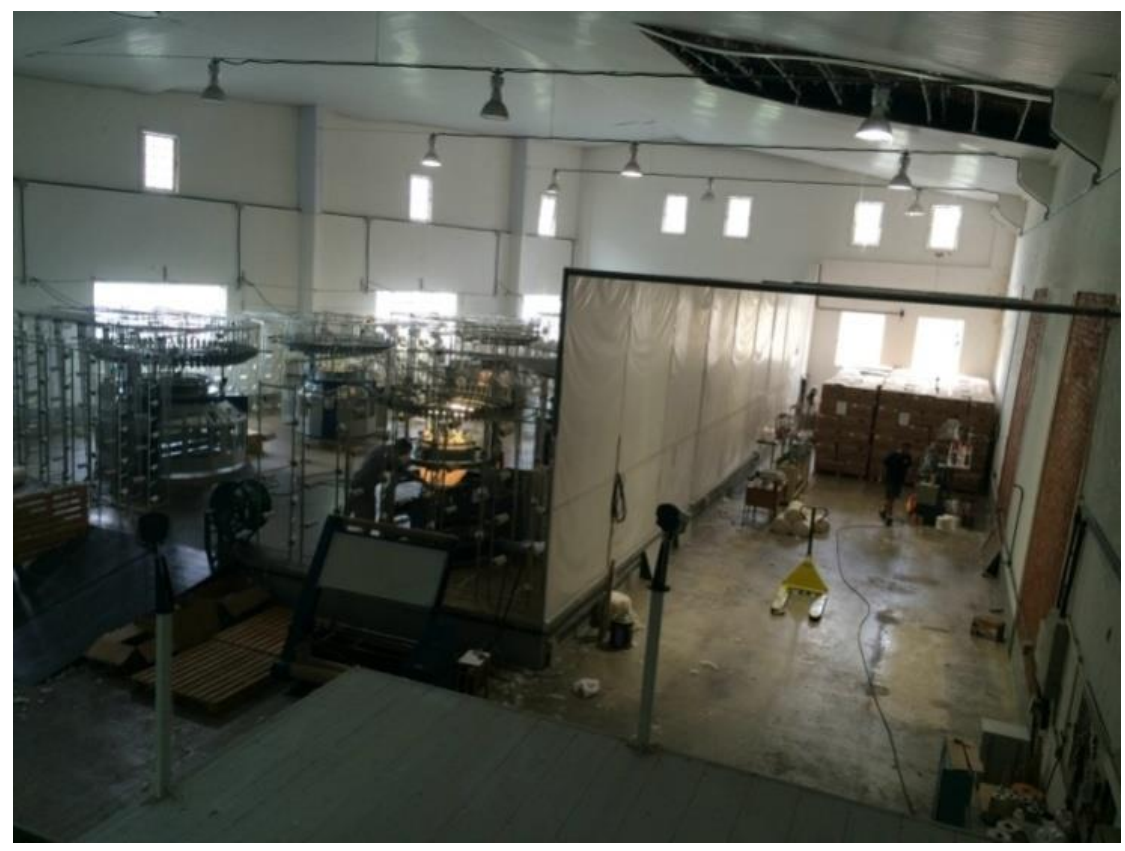

Figura 6 - Retirada da Seção Retilínea Fonte: Empresa

\subsubsection{Alteração do Layout}

Inicialmente, foi elaborado um projeto para modificar as gaiolas laterais em forma de 'U', para uma alimentação em 'L' (Figura 8). Para realizar esse procedimento, foi 
Custos de produção de artigos têxteis e Avaliação da possibilidade de terceirização da fabricação após a reorganização do arranjo físico Marcelo Aguiar Baptista, Allan Jonathan da Silva, Fabini Hoelz Bargas Alvarez

necessária a compra de material de gaiola e 10 horas extras por parte de 2 operadores. Com essa mudança, conseguiu-se aproveitar melhor o espaço, fazendo-se com que o tear nove, que anteriormente ficava a 15 metros de distância e em diferente nível, deslocou-se para o nível superior e a 3 metros de distância dos demais teares. Com os oito teares agora juntos e as gaiolas organizadas em ' $L$ ', abriu-se o campo de visão de forma que o trabalhador, que antes visualizava apenas um tear, agora possa ter a visão de quatro deles. Em relação à alimentação dos teares, abriu-se um amplo espaço para o transporte de matéria prima e material acabado, facilitando assim as operações.

A seção retilínea deslocou-se de sua localização original, realocando-se no local de estoque para matéria prima. Para isso, foi necessário o trabalho de três dias de um eletricista para realocar a rede elétrica e o transporte interno dos teares pelos operadores. Dessa forma, derrubou-se a antiga parede de metalon, melhorando a circulação de ar, e os resíduos que prejudicavam a seção retilínea acabaram. Nessa mudança de layout, conseguiu-se melhorar a produção circular em 12\%, houve pequena melhora nos tipos de defeito, como raleiras e falhas de agulha, que acontecem quando a máquina produz uma peça sem a vistoria do operador. O tecelão responsável pela seção retilínea demonstrou satisfação e motivação com a mudança, diminuindo os defeitos e melhorando sua produção. 
Custos de produção de artigos têxteis e Avaliação da possibilidade de terceirização da fabricação após a reorganização do arranjo físico Marcelo Aguiar Baptista, Allan Jonathan da Silva, Fabini Hoelz Bargas Alvarez

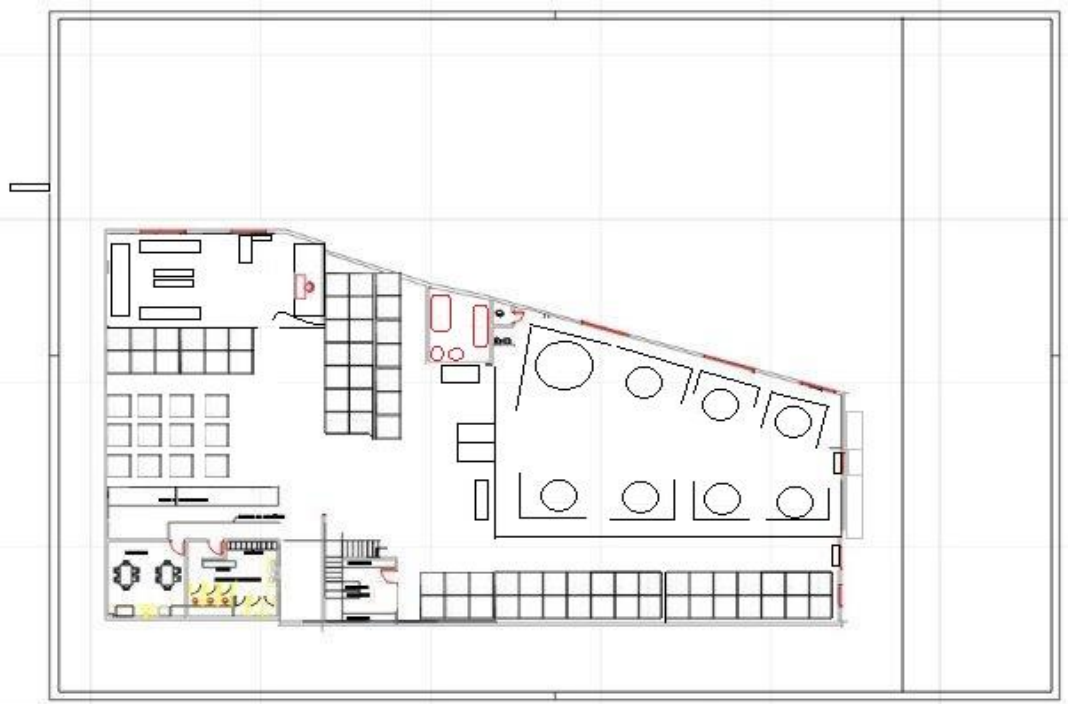

Figura 7 - Novo Layout

Fonte: Autor

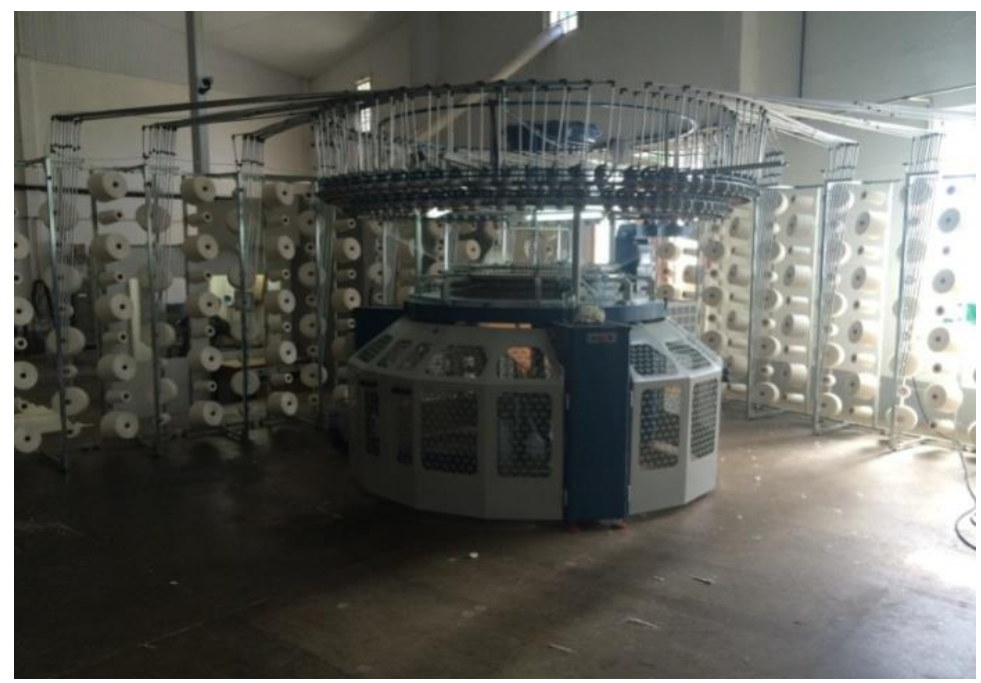

Figura 8 - Gaiolas de alimentação em 'L' Fonte: Empresa 
Custos de produção de artigos têxteis e Avaliação da possibilidade de terceirização da fabricação após a reorganização do arranjo físico

Marcelo Aguiar Baptista, Allan Jonathan da Silva, Fabini Hoelz Bargas Alvarez

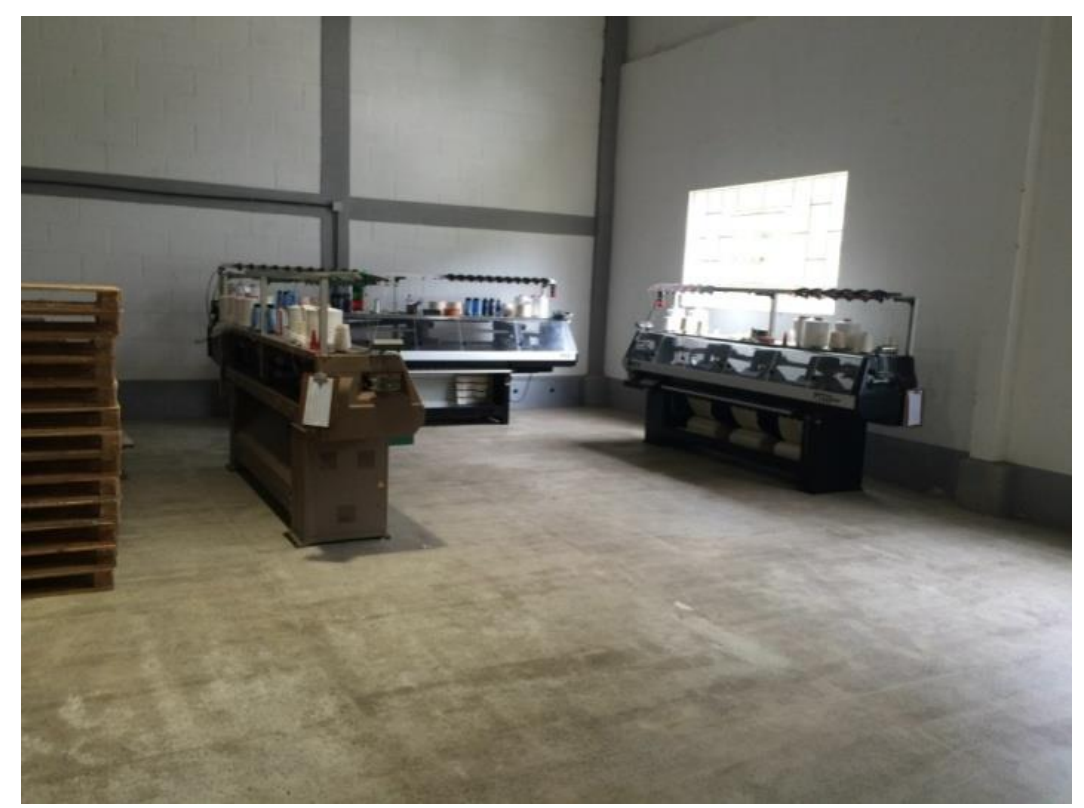

Figura 9 - Nova localização da Seção Retilínea Fonte: Empresa

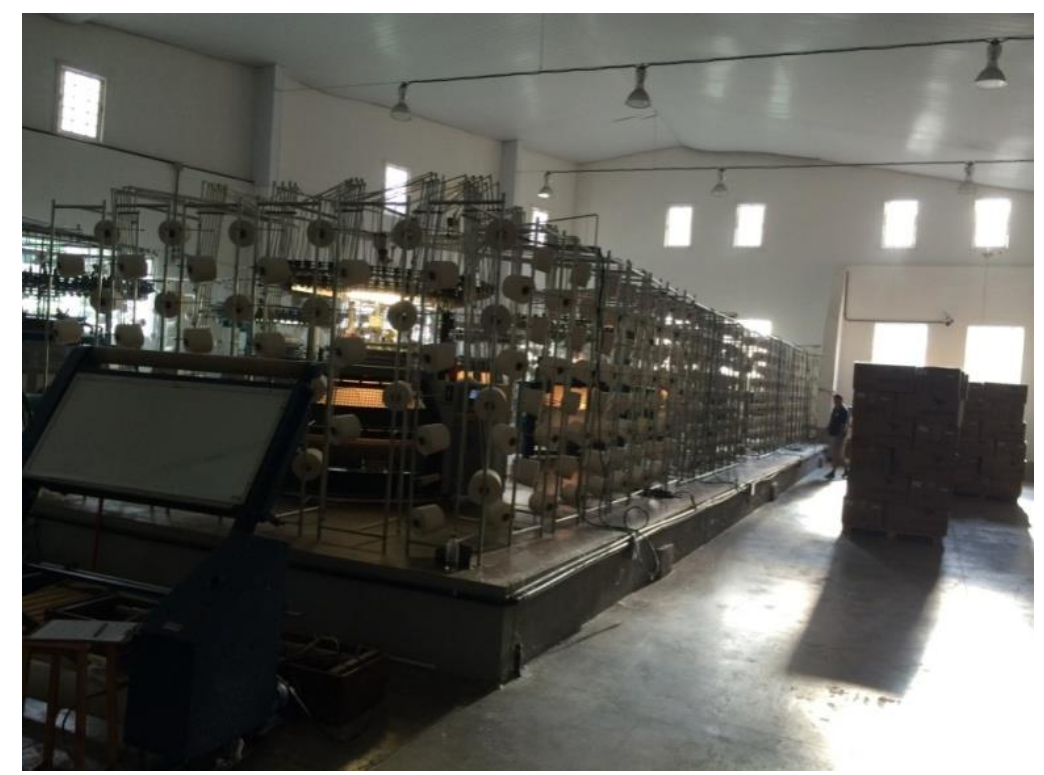

Figura 10 - Remoção da parede e alocação do estoque. Fonte: Empresa

\subsubsection{Resíduos Gerados}

A produção circular consome uma grande quantidade de fios de algodão diariamente. Ao passar pelos alimentadores dos teares circulares, os fios liberam 
Custos de produção de artigos têxteis e Avaliação da possibilidade de terceirização da fabricação após a reorganização do arranjo físico Marcelo Aguiar Baptista, Allan Jonathan da Silva, Fabini Hoelz Bargas Alvarez

resíduos de algodão e cascas do mesmo. Considerando que cada um dos oito teares possui 96 alimentadores, temos 768 fontes de alimentação que eliminam esses resíduos. Tais resíduos são muito leves, por isso ficam flutuando até caírem sobre outros teares ou sobre o chão, pelo fato de o galpão ter uma circulação de ar natural com janelas, portanto variável de acordo com o clima.

\subsubsection{Novo Gerenciamento de Resíduos}

A Empresa está localizada à margem de um rio. Tentou-se utilizar o vento a favor, abrindo algumas janelas para tentar fazer com que essa poeira seguisse uma mesma direção. O grande problema é que o vento mudava constantemente de direção, fazendo com que essa poeira circulasse no ambiente. Com o intuito de solucionar o problema, foram instalados 2 ventiladores industriais do lado norte do galpão e dois exaustores do lado sul. Todas as janelas foram fechadas no intuito de se fazer um corredor de ar capaz de captar e expelir toda a poeira e os resíduos provenientes dos fios de algodão.

\subsubsection{Alimentação dos Teares utilizada}

A forma de alimentação dos tearesimpacta diretamente na produção. Todo tear possui uma gaiola lateral com seus devidos alimentadores e os alimentadores reservas. O tecelão principal não tinha um planejamento, e solicitava que o auxiliar alimentasse os teares somente no final dos cones de fio. Como os teares funcionam em diferentes velocidades (RPM), muitas vezes a matéria prima acabava em vários teares ao mesmo tempo, fazendo com que o auxiliar não conseguisse realizar toda a alimentação, deixando assim a produção parada.

\subsubsection{Nova Metodologia de Alimentação}

Todos os teares circulares precisam aquecer o motor antes de rodar em sua velocidade máxima. Esse período de aquecimento ocorre das $7 \mathrm{~h}$ às $8 \mathrm{~h}$. Como toda gaiola lateral possui o alimentador e um reserva, decidiu-se alimentar todos os reservas e amarrá-los aos alimentadores principais. São utilizados os dois auxiliares de produção 
Custos de produção de artigos têxteis e Avaliação da possibilidade de terceirização da fabricação após a reorganização do arranjo físico Marcelo Aguiar Baptista, Allan Jonathan da Silva, Fabini Hoelz Bargas Alvarez

para coletar a matéria prima no estoque e alimentar os oito teares durante esse horário, com a ajuda do tecelão responsável por cada tear. Dessa forma, não ocorrem mais paradas repentinas durante a jornada de trabalho, pois a carga alimentada é suficiente para atender a produção diária, evitando retardo na produção.

\subsection{Aplicação do Método ABC}

Uma atividade é uma ação que utiliza os recursos humanos e, materiais tecnológicos e financeiros para se produzirem bens ou serviços. É composta por um conjunto de tarefas necessárias ao desempenho. Num departamento, são executadas atividades homogêneas. O primeiro passo, para o custeio $A B C$, é identificar as atividades relevantes dentro de cada departamento.

A organização se divide em centros de custos, por exemplo: Produção, Manutenção e Administração Geral, e cada centro de custo possui suas atividades relevantes. Então serão identificadas as seguintes atividades relevantes:

Tabela 1 - Atividades Relevantes

\begin{tabular}{|c|c|}
\hline \multicolumn{2}{|c|}{ Levantamento das atividades relevantes dos departamentos } \\
\hline Departamentos & Atividades \\
\hline Produção & Alimentação \\
& Expedição \\
& Operar Tear \\
& Consumo Tear \\
\hline Manutenção & Insumos \\
& Mao de obra \\
\hline Administração Geral & Aluguel \\
& Salário Administração \\
& Telefone \\
& Água \\
\hline
\end{tabular}

Fonte: Empresa 
Custos de produção de artigos têxteis e Avaliação da possibilidade de terceirização da fabricação após a reorganização do arranjo físico Marcelo Aguiar Baptista, Allan Jonathan da Silva, Fabini Hoelz Bargas Alvarez

\section{LEVANTAMENTO DE DADOS}

É importante ressaltar que, neste estudo de 24 meses, houveram alterações na equipe, aumento de preços de produtos, serviços e de alguns custos e também reajustes nas folhas de pagamento.

Neste trabalho, iremos estudar toda a produção do artigo Meia Malha referente aos teares circulares 5, 6 e 7, pois o restante dos teares produz artigos diferenciados. Por isso, por simplificação, iremos supor que só existem os três teares mencionados acima produzindo na empresa, focando num só artigo.

O tear 5 é da marca Mayer, modelo Mv1, fabricado em 1991, e seu consumo é de $4,7 \mathrm{KW} / \mathrm{h}$. O tear 6 é da marca Orizio, modelo $\mathrm{JOHN}$, fabricado em 1999, e seu consumo é de 7,5 KW/h. O tear 7 é da marca Mayer, modelo S4, fabricado em 2007, e possui um consumo de $5,5 \mathrm{KW} / \mathrm{h}$.

Serão usados os dados de janeiro de 2013 a dezembro de 2014. A média de produção dos teares citados consta na tabela a seguir:

Tabela 2- Média da Produção Mensal

\begin{tabular}{|c|c|c|}
\hline MEDIA & & \\
PRODUÇÃO & 2013 & 2014 \\
\hline Tear cinco & $2538,08 \mathrm{Kg}$ & $2727,08 \mathrm{~kg}$ \\
\hline Tear 6 & $2721,48 \mathrm{~kg}$ & $2904,95 \mathrm{~kg}$ \\
\hline Tear 7 & $3517,90 \mathrm{~kg}$ & $3106,32 \mathrm{~kg}$ \\
\hline
\end{tabular}

Fonte: Empresa

Pode-se perceber que, com as melhorias citadas anteriormente, a média de produção dos teares 5 e 6 aumentou, enquanto que seu tempo de funcionamento diminuiu.

A produtividade, medida em quantidade produzida em $\mathrm{Kg}$ por tempo de funcionamento dos teares, está exposta na tabela a seguir. 
Custos de produção de artigos têxteis e Avaliação da possibilidade de terceirização da fabricação após a reorganização do arranjo físico Marcelo Aguiar Baptista, Allan Jonathan da Silva, Fabini Hoelz Bargas Alvarez

Tabela 3- Média da Produtividade Mensal

\begin{tabular}{|c|c|c|}
\hline PRODUTIVIDADE & 2013 & 2014 \\
\hline Tear 5 & 11,1 & 13,1 \\
\hline Tear 6 & 12,25 & 13,97 \\
\hline Tear 7 & 15,76 & 14,97 \\
\hline
\end{tabular}

Fonte: Empresa

O tear 7 é o tear mais produtivo da empresa, como se pode observar nas duas tabelas acima. A redução observada do tear 7 , em ambas as tabelas acima, pode ser explicada pelas seguintes razões:

- Mudança do operador do tear;

- Lote de matéria prima inferior ao lote do ano de 2013;

- Defeitos ocasionados pela baixa qualidade de matéria prima.

A empresa possui três departamentos: Produção, Manutenção e Administração Geral.No Departamento de Produção, tem-se as seguintes atividades: "Alimentação dos Teares" e "Expedição do produto acabado", calculados com base no tempo gasto pelo funcionário para alimentar cada tear e para fazer a expedição. Estes tempos serão aplicados e seu salário rateado, tendo como direcionadores o HH (Hora Homem) do operador. O tempo médio do funcionário é de 7,5 minutos, tanto para a expedição quanto para a alimentação. Nas duas tabelas a seguir, encontram-se os tempos das atividades do operador responsável por alimentar os teares e por expedir a matéria prima, junto com valor de seu salário para facilitar o entendimento dos valores $\mathrm{HH}$.

Além destas atividades, a "Operação do Tear" tem como direcionador o HH dos teares (valor da mão de obra do tecelão). Os teares 5 e 6 são operados pelo mesmo tecelão, e $\circ 7$ é operado por outro tecelão que se divide em mais um tear. Para o cálculo de $\mathrm{HH}$, rateou-se o salário do operador pelos dois teares operados para descobrir o valor de operação mensal do tear. Feito isso, dividiu-se pela quantidade de horas trabalhadas para encontrar o valor de operação do tear por hora.

Por último, tem-se a atividade "Funcionamento do tear". Foram analisadas todas as contas de consumo de energia elétrica dos 24 meses e colocadas as tarifas tanto em 
Custos de produção de artigos têxteis e Avaliação da possibilidade de terceirização da fabricação após a reorganização do arranjo físico Marcelo Aguiar Baptista, Allan Jonathan da Silva, Fabini Hoelz Bargas Alvarez

horário de ponta (19hs -21hs) quanto no horário fora de ponta. Conhecendo-se o consumo de cada tear, este foi multiplicadopela quantidade de horas trabalhadas e pela tarifa, para então se descobrir o valor de seu direcionador HM (Hora Máquina) de cada tear.

Tabela 4 - Dados do Auxiliar e das atividades

2013

\begin{tabular}{|c|c|c|c|c|c|c|c|}
\hline Operador & Salário & Horas & $\mathbf{\$} / \mathbf{H}$ & $\begin{array}{c}\text { t expedir } \\
\text { (min.) }\end{array}$ & $\begin{array}{c}\text { t alim } \\
\text { (min.) }\end{array}$ & $\begin{array}{c}\mathbf{\$} \text { maq. } \\
\text { exp. }\end{array}$ & $\mathbf{\$}$ maq. alim \\
\hline JAN & $\mathrm{R} \$ 750,00$ & 200 & $\mathbf{3 , 7 5}$ & 7,5 & 7,5 & $\mathbf{0 , 5 0}$ & $\mathbf{0 , 5 0}$ \\
\hline $\mathrm{FEV}$ & $\mathrm{R} \$ 750,00$ & 200 & $\mathbf{3 , 7 5}$ & 7,5 & 7,5 & $\mathbf{0 , 5 0}$ & $\mathbf{0 , 5 0}$ \\
\hline $\mathrm{MAR}$ & $\mathrm{R} \$ 750,00$ & 160 & $\mathbf{4 , 6 9}$ & 7,5 & 7,5 & $\mathbf{0 , 6 3}$ & $\mathbf{0 , 6 3}$ \\
\hline $\mathrm{ABR}$ & $\mathrm{R} \$ 750,00$ & 170 & $\mathbf{4 , 4 1}$ & 7,5 & 7,5 & $\mathbf{0 , 5 9}$ & $\mathbf{0 , 5 9}$ \\
\hline $\mathrm{MAl}$ & $\mathrm{R} \$ 750,00$ & 210 & $\mathbf{3 , 5 7}$ & 7,5 & 7,5 & $\mathbf{0 , 4 8}$ & $\mathbf{0 , 4 8}$ \\
\hline $\mathrm{JUN}$ & $\mathrm{R} \$ 750,00$ & 190 & $\mathbf{3 , 9 5}$ & 7,5 & 7,5 & $\mathbf{0 , 5 3}$ & $\mathbf{0 , 5 3}$ \\
\hline $\mathrm{JUL}$ & $\mathrm{R} \$ 750,00$ & 210 & $\mathbf{3 , 5 7}$ & 7,5 & 7,5 & $\mathbf{0 , 4 8}$ & $\mathbf{0 , 4 8}$ \\
\hline $\mathrm{AGO}$ & $\mathrm{R} \$ 750,00$ & 210 & $\mathbf{3 , 5 7}$ & 7,5 & 7,5 & $\mathbf{0 , 4 8}$ & $\mathbf{0 , 4 8}$ \\
\hline $\mathrm{SET}$ & $\mathrm{R} \$ 750,00$ & 220 & $\mathbf{3 , 4 1}$ & 7,5 & 7,5 & $\mathbf{0 , 4 5}$ & $\mathbf{0 , 4 5}$ \\
\hline $\mathrm{OUT}$ & $\mathrm{R} \$ 750,00$ & 220 & $\mathbf{3 , 4 1}$ & 7,5 & 7,5 & $\mathbf{0 , 4 5}$ & $\mathbf{0 , 4 5}$ \\
\hline $\mathrm{NOV}$ & $\mathrm{R} \$ 750,00$ & 190 & $\mathbf{3 , 9 5}$ & 7,5 & 7,5 & $\mathbf{0 , 5 3}$ & $\mathbf{0 , 5 3}$ \\
\hline $\mathrm{DEZ}$ & $\mathrm{R} \$ 750,00$ & 150 & $\mathbf{5 , 0 0}$ & 7,5 & 7,5 & $\mathbf{0 , 6 7}$ & $\mathbf{0 , 6 7}$ \\
\hline
\end{tabular}

Fonte: Empresa

Tabela 5- Dados do Auxiliar e das atividades

2014

\begin{tabular}{|c|c|c|c|c|c|c|c|}
\hline Operador & Salário & Horas & $\mathbf{\$} / \mathbf{H}$ & $\begin{array}{c}\text { t expedir } \\
\text { (min.) }\end{array}$ & $\begin{array}{c}\text { t alim } \\
\text { (min.) }\end{array}$ & $\begin{array}{c}\mathbf{\$} \text { maq. } \\
\text { exp. }\end{array}$ & $\mathbf{\$}$ maq. alim \\
\hline JAN & $\mathrm{R} \$ 750,00$ & 200 & $\mathbf{3 , 7 5}$ & 7,5 & 7,5 & $\mathbf{0 , 5 0}$ & $\mathbf{0 , 5 0}$ \\
\hline $\mathrm{FEV}$ & $\mathrm{R} \$ 750,00$ & 200 & $\mathbf{3 , 7 5}$ & 7,5 & 7,5 & $\mathbf{0 , 5 0}$ & $\mathbf{0 , 5 0}$ \\
\hline $\mathrm{MAR}$ & $\mathrm{R} \$ 750,00$ & 160 & $\mathbf{4 , 6 9}$ & 7,5 & 7,5 & $\mathbf{0 , 6 3}$ & $\mathbf{0 , 6 3}$ \\
\hline $\mathrm{ABR}$ & $\mathrm{R} \$ 880,00$ & 170 & $\mathbf{5 , 1 8}$ & 7,5 & 7,5 & $\mathbf{0 , 6 9}$ & $\mathbf{0 , 6 9}$ \\
\hline $\mathrm{MAl}$ & $\mathrm{R} \$ 880,00$ & 210 & $\mathbf{4 , 1 9}$ & 7,5 & 7,5 & $\mathbf{0 , 5 6}$ & $\mathbf{0 , 5 6}$ \\
\hline $\mathrm{JUN}$ & $\mathrm{R} \$ 880,00$ & 190 & $\mathbf{4 , 6 3}$ & 7,5 & 7,5 & $\mathbf{0 , 6 2}$ & $\mathbf{0 , 6 2}$ \\
\hline $\mathrm{JUL}$ & $\mathrm{R} \$ 880,00$ & 210 & $\mathbf{4 , 1 9}$ & 7,5 & 7,5 & $\mathbf{0 , 5 6}$ & $\mathbf{0 , 5 6}$ \\
\hline $\mathrm{AGO}$ & $\mathrm{R} \$ 880,00$ & 210 & $\mathbf{4 , 1 9}$ & 7,5 & 7,5 & $\mathbf{0 , 5 6}$ & $\mathbf{0 , 5 6}$ \\
\hline $\mathrm{SET}$ & $\mathrm{R} \$ 880,00$ & 220 & $\mathbf{4 , 0 0}$ & 7,5 & 7,5 & $\mathbf{0 , 5 3}$ & $\mathbf{0 , 5 3}$ \\
\hline $\mathrm{OUT}$ & $\mathrm{R} \$ 880,00$ & 220 & $\mathbf{4 , 0 0}$ & 7,5 & 7,5 & $\mathbf{0 , 5 3}$ & $\mathbf{0 , 5 3}$ \\
\hline $\mathrm{NOV}$ & $\mathrm{R} \$ 880,00$ & 190 & $\mathbf{4 , 6 3}$ & 7,5 & 7,5 & $\mathbf{0 , 6 2}$ & $\mathbf{0 , 6 2}$ \\
\hline $\mathrm{DEZ}$ & $\mathrm{R} \$ 880,00$ & 150 & $\mathbf{5 , 8 7}$ & 7,5 & 7,5 & $\mathbf{0 , 7 8}$ & $\mathbf{0 , 7 8}$ \\
\hline
\end{tabular}

Fonte: Empresa 
Custos de produção de artigos têxteis e Avaliação da possibilidade de terceirização da fabricação após a reorganização do arranjo físico Marcelo Aguiar Baptista, Allan Jonathan da Silva, Fabini Hoelz Bargas Alvarez

Na Tabela 6 tem-se a quantidade de horas trabalhadas nos dois anos de análise. Considerando-se que todos os teares tiveram o mesmo funcionamento, tem-se:

Tabela 6 - Dias e Horas trabalhadas

\begin{tabular}{|c|c|c|c|c|c|}
\hline & Dias & Horas Diárias & Horas trabalhadas & Horas Extras & Horas Manutenção \\
\hline 2013 & 232 & 10 & 2320 & 359 & 112 \\
\hline 2014 & 233 & 10 & 2330 & 165 & 112 \\
\hline
\end{tabular}

Fonte: Empresa

A fim de exemplificar o cálculo de consumo do tear, segue uma Tabela exemplo do tear 5 no ano de 2013:

Tabela 7- Quadro de consumo de Energia Elétrica

\begin{tabular}{|c|c|c|c|c|c|c|c|c|}
\hline $\begin{array}{c}\text { TEAR } \\
5 \\
\end{array}$ & & & & & & & & \\
\hline 2013 & kWh & Hr trab. & Tarifa $\mathbf{R} \$$ & $\begin{array}{l}\text { Valor } \\
\text { Pago }\end{array}$ & Hr Extra & Tarifa $\mathbf{R} \$$ & $\begin{array}{l}\text { Valor } \\
\text { Pago }\end{array}$ & HM \\
\hline Jan. & 4,7 & 190 & 0,1877 & $R \$ 167,62$ & 16 & 2,0993 & $R \$ 157,87$ & $R \$ 325,48$ \\
\hline Fev. & 4,7 & 150 & 0,1517 & $R \$ 106,95$ & 11 & 1,8096 & $R \$ 93,56$ & $R \$ 200,50$ \\
\hline Mar. & 4,7 & 190 & 0,1492 & $R \$ 133,24$ & 13 & 1,7803 & $\mathrm{R} \$ 108,78$ & $R \$ 242,01$ \\
\hline Abr. & 4,7 & 200 & 0,2149 & $\mathrm{R} \$ 202,01$ & 15 & 2,2378 & $\mathrm{R} \$ 157,76$ & $\mathrm{R} \$ \mathbf{3 5 9 , 7 7}$ \\
\hline Maio & 4,7 & 210 & 0,2156 & $R \$ 212,80$ & 29 & 2,2273 & $\mathrm{R} \$ 303,58$ & $R \$ 516,38$ \\
\hline Jun. & 4,7 & 200 & 0,2114 & $R \$ 198,72$ & 39 & 2,1838 & $R \$ 400,29$ & $\mathrm{R} \$ 599,01$ \\
\hline Jul. & 4,7 & 230 & 0,2193 & $\mathrm{R} \$ 237,06$ & 54 & 2,2656 & $\mathrm{R} \$ 575,01$ & $\mathrm{R} \$ \mathbf{8 1 2 , 0 7}$ \\
\hline Ago. & 4,7 & 190 & 0,2174 & $\mathrm{R} \$ 194,14$ & 42 & 2,2461 & $R \$ 443,38$ & $\mathrm{R} \$ \mathbf{6 3 7 , 5 2}$ \\
\hline Set. & 4,7 & 210 & 0,1984 & $R \$ 195,82$ & 47 & 2,0501 & $R \$ 452,87$ & $R \$ 648,69$ \\
\hline Out. & 4,7 & 230 & 0,2044 & $\mathrm{R} \$ 220,96$ & 51 & 2,1112 & $\mathrm{R} \$ 506,05$ & $\mathrm{R} \$ 727,01$ \\
\hline Nov. & 4,7 & 190 & 0,1952 & $\mathrm{R} \$ 174,31$ & 42 & 2,212 & $R \$ 436,65$ & $R \$ 610,96$ \\
\hline Dez. & 4,7 & 130 & 0,1902 & $\mathrm{R} \$ 116,21$ & 0 & 2,1555 & $R \$ \mathbf{0 , 0 0}$ & $R \$ 116,21$ \\
\hline
\end{tabular}

Fonte: Empresa

No Departamento de Manutenção há o gasto "Insumos" que têm como direcionador o valor das agulhas, multiplicados pela quantidade que foi trocada. Tem-se também a "Mão de obra de Manutenção", cujo direcionador é o HH dos funcionários que realizam a tarefa. A manutenção é feita na empresa duas vezes ao ano, sempre 
Custos de produção de artigos têxteis e Avaliação da possibilidade de terceirização da fabricação após a reorganização do arranjo físico Marcelo Aguiar Baptista, Allan Jonathan da Silva, Fabini Hoelz Bargas Alvarez

fora do horário de trabalho e sempre acompanhada por dois tecelões. Por ser uma atividade extra, iremos nos basear no valor da hora-extra do funcionário, que consiste no valor de seu $\mathrm{HH}$ de operação, acrescido de $50 \%$. Os valores das agulhas utilizadas em 2013 foram:

-Tear 5 - $\mathrm{R} \$ 2,50$ / unidade.

-Tear 6- $\mathrm{R} \$ 2,70 /$ unidade

-Tear 7- $\mathrm{R} \$ 2,80$ / unidade.

No ano de 2014, houve um aumento, porém, como a empresa já tinha comprado uma quantidade considerável em alguns teares, adotaram-se os seguintes valores:

-Tear 5 - $\mathrm{R} \$ 2,70$ / unidade.

-Tear 6- $\mathrm{R} \$ 2,70$ / unidade.

-Tear 7- $\mathrm{R} \$ 3,02$ / unidade.

No Departamento de Administração, tem-se o gasto "Aluguel", que tem como direcionador a área ocupada pelo tear. Para isso, foram utilizados os valores de aluguel dos 24 meses, divididos pela área ocupada pela empresa, para descobrir o valor do metro quadrado. A partir daí, foram multiplicados pela área ocupada pelo tear; o gasto "Salário da Administração", tendo como direcionador o HH dos três administradores da empresa. Para a obtenção do valor, foram divididos os três salários pela quantidade de horas trabalhadas. Para "Custo telefone" e "Custo água", foi feita uma relação com a quantidade produzida. $\mathrm{O}$ valor das contas de telefone foi dividido pela quantidade produzida de cada tear para encontrar o custo de telefone por cada quilograma de Meia Malha. Como a empresa fica localizada num parque industrial, há uma taxa fixa de água. Assim como no telefone, esse valor foi divido pela quantidade de Meia Malha produzida em cada tear.

\section{ANÁLISE DOS RESULTADOS}

São apresentadas três tabelas, comparando o custo do produto de cada tear de acordo com o ano. 
Custos de produção de artigos têxteis e Avaliação da possibilidade de terceirização da fabricação após a reorganização do arranjo físico

Marcelo Aguiar Baptista, Allan Jonathan da Silva, Fabini Hoelz Bargas Alvarez

Tabela 8 - Comparativo Tear 5

M5
\begin{tabular}{|l|r|r|r|}
\hline $\mathbf{2 0 1 3}$ & $\begin{array}{c}\text { Quantidade } \\
\text { produzida } \\
\text { (kg) }\end{array}$ & $\begin{array}{c}\text { Custos } \\
\mathbf{R} \mathbf{\$}\end{array}$ & Custos/qtd. \\
\hline Jan. & 2364,80 & 1548,21 & 0,65 \\
\hline Fev. & 1440,95 & 1394,70 & 0,97 \\
\hline Mar. & 2423,27 & 1361,52 & 0,56 \\
\hline Abr. & 2181,15 & 1571,11 & 0,72 \\
\hline Maio & 2544,63 & 1948,71 & 0,77 \\
\hline Jun. & 2533,12 & 2063,94 & 0,81 \\
\hline Jul. & 2814,84 & 2198,94 & 0,78 \\
\hline Ago. & 3226,66 & 1938,38 & 0,60 \\
\hline Set. & 3621,58 & 2025,45 & 0,56 \\
\hline Out. & 3830,53 & 2111,07 & 0,55 \\
\hline Nov. & 2630,16 & 2098,77 & 0,80 \\
\hline Dez. & 845,35 & 1025,62 & 1,21 \\
\hline
\end{tabular}

M5
\begin{tabular}{|l|r|r|r|}
\hline 2014 & $\begin{array}{c}\text { Quantidade } \\
\text { produzida } \\
\text { (kg) }\end{array}$ & Custos R\$ & Custos/qtd. \\
\hline Jan. & 2626,07 & 1238,45 & 0,47 \\
\hline Fev. & 2549,65 & 1237,76 & 0,49 \\
\hline Mar. & 2474,71 & 1298,45 & 0,52 \\
\hline Abr. & 2853,75 & 1737,88 & 0,61 \\
\hline Maio & 3009,65 & 1736,39 & 0,58 \\
\hline Jun. & 2956,66 & 1612,16 & 0,55 \\
\hline Jul. & 3006,94 & 1857,38 & 0,62 \\
\hline Ago. & 2813,37 & 1954,58 & 0,69 \\
\hline Set. & 2913,13 & 1762,01 & 0,60 \\
\hline Out. & 3628,38 & 1654,81 & 0,46 \\
\hline Nov. & 2678,67 & 1598,03 & 0,60 \\
\hline Dez. & 1214,08 & 1291,09 & 1,06 \\
\hline
\end{tabular}

\begin{tabular}{|r|r|}
\hline $\begin{array}{c}\text { Dif. } \\
\mathbf{1 4 - 1 3}\end{array}$ & \multicolumn{1}{c|}{$\%$} \\
\hline$-0,18$ & $-14,2 \%$ \\
\hline$-0,48$ & $-30,0 \%$ \\
\hline$-0,04$ & $-3,0 \%$ \\
\hline$-0,11$ & $-7,3 \%$ \\
\hline$-0,19$ & $-12,3 \%$ \\
\hline$-0,27$ & $-17,4 \%$ \\
\hline$-0,16$ & $-10,2 \%$ \\
\hline 0,09 & $6,3 \%$ \\
\hline 0,05 & $3,4 \%$ \\
\hline$-0,10$ & $-8,2 \%$ \\
\hline$-0,20$ & $-12,6 \%$ \\
\hline$-0,15$ & $-5,7 \%$ \\
\hline & \\
\hline$-0,15$ & $-9,3 \%$ \\
\hline
\end{tabular}

Fonte: Autor

Tabela 9 - Comparativo Tear 6

\begin{tabular}{|c|c|c|c|}
\hline 2013 & \begin{tabular}{|c|}
$\begin{array}{c}\text { Quantidade } \\
\text { produzida } \\
\text { (kg) }\end{array}$ \\
\end{tabular} & Custos R\$ & Custos/qtd \\
\hline Jan. & 2544,59 & 1603,63 & 0,63 \\
\hline Fev. & 2166,44 & 1505,32 & 0,69 \\
\hline Mar. & 2932,41 & 1842,78 & 0,63 \\
\hline Abr. & 2592,00 & 1946,60 & 0,75 \\
\hline Maio & 2265,79 & 2112,13 & 0,93 \\
\hline Jun. & 2613,78 & 2535,79 & 0,97 \\
\hline Jul. & 3431,47 & 3088,90 & 0,90 \\
\hline Ago. & 2573,23 & 2487,71 & 0,97 \\
\hline Set. & 3469,46 & 2365,69 & 0,68 \\
\hline Out. & 3561,89 & 2599,33 & 0,73 \\
\hline Nov. & 2895,71 & 2922,68 & 1,01 \\
\hline Dez. & 1611,11 & 1230,79 & 0,76 \\
\hline
\end{tabular}

M6
\begin{tabular}{|l|r|r|r|}
\hline $\mathbf{2 0 1 4}$ & $\begin{array}{c}\text { Quantidade } \\
\text { produzida } \\
\text { (kg) }\end{array}$ & Custos R\$ & Custos/qtd \\
\hline Jan. & 2683,29 & 1551,94 & 0,58 \\
\hline Fev. & 2753,95 & 1599,11 & 0,58 \\
\hline Mar. & 2333,90 & 1632,52 & 0,70 \\
\hline Abr. & 2686,49 & 2143,85 & 0,80 \\
\hline Maio & 3438,22 & 2219,11 & 0,65 \\
\hline Jun. & 3020,89 & 2118,47 & 0,70 \\
\hline Jul. & 2783,42 & 2418,35 & 0,87 \\
\hline Ago. & 3063,46 & 2593,39 & 0,85 \\
\hline Set. & 3435,83 & 2176,96 & 0,63 \\
\hline Out. & 3757,54 & 2010,98 & 0,54 \\
\hline Nov. & 3170,95 & 2060,49 & 0,65 \\
\hline Dez. & 1731,53 & 1572,77 & 0,91 \\
\hline
\end{tabular}

Fonte: Autor

\begin{tabular}{|c|c|}
\hline $\begin{array}{c}\text { Dif } \\
\mathbf{1 4 - 1 3}\end{array}$ & \multicolumn{1}{c|}{$\%$} \\
\hline$-0,05$ & $-3,7 \%$ \\
\hline$-0,11$ & $-7,8 \%$ \\
\hline 0,07 & $4,7 \%$ \\
\hline 0,05 & $2,6 \%$ \\
\hline$-0,29$ & $-16,0 \%$ \\
\hline$-0,27$ & $-14,1 \%$ \\
\hline$-0,03$ & $-1,5 \%$ \\
\hline$-0,12$ & $-5,8 \%$ \\
\hline$-0,05$ & $-3,2 \%$ \\
\hline$-0,19$ & $-13,5 \%$ \\
\hline$-0,36$ & $-19,1 \%$ \\
\hline 0,14 & $7,5 \%$ \\
\hline & \\
\hline$-0,10$ & $-5,8 \%$ \\
\hline
\end{tabular}

MÉDIA 
Custos de produção de artigos têxteis e Avaliação da possibilidade de terceirização da fabricação após a reorganização do arranjo físico Marcelo Aguiar Baptista, Allan Jonathan da Silva, Fabini Hoelz Bargas Alvarez

Tabela 10 - Comparativo Tear 7

M7
\begin{tabular}{|l|r|r|r|}
\hline $\mathbf{2 0 1 3}$ & $\begin{array}{c}\text { Quantidade } \\
\text { Produzida } \\
\text { (kg) }\end{array}$ & Custos R\$ & Custos/qtd \\
\hline Jan. & 3175,61 & 1676,89 & 0,53 \\
\hline Fev. & 2701,15 & 1480,79 & 0,55 \\
\hline Mar. & 3470,27 & 1906,12 & 0,55 \\
\hline Abr. & 3430,66 & 2064,89 & 0,60 \\
\hline Maio & 3419,82 & 2208,70 & 0,65 \\
\hline Jun. & 3394,04 & 2343,10 & 0,69 \\
\hline Jul. & 4366,86 & 2618,12 & 0,60 \\
\hline Ago. & 4021,34 & 2237,23 & 0,56 \\
\hline Set. & 4323,34 & 2231,54 & 0,52 \\
\hline Out. & 4503,80 & 2418,51 & 0,54 \\
\hline Nov. & 3487,89 & 2384,68 & 0,68 \\
\hline Dez. & 1920,10 & 1322,57 & 0,69 \\
\hline
\end{tabular}

M7
\begin{tabular}{|l|r|r|r|}
\hline $\mathbf{2 0 1 4}$ & $\begin{array}{c}\text { Quantidade } \\
\text { produzida } \\
\text { (kg) }\end{array}$ & Custos R\$ & Custos/qtd \\
\hline Jan. & 2758,99 & 1375,70 & 0,50 \\
\hline Fev. & 2771,47 & 1423,85 & 0,51 \\
\hline Mar. & 2953,26 & 1432,96 & 0,49 \\
\hline Abr. & 2291,87 & 1617,74 & 0,71 \\
\hline Maio & 2959,72 & 1835,72 & 0,62 \\
\hline Jun. & 2467,53 & 1867,35 & 0,76 \\
\hline Jul. & 3933,11 & 2353,73 & 0,60 \\
\hline Ago. & 3617,19 & 2154,96 & 0,60 \\
\hline Set. & 4054,30 & 1950,64 & 0,48 \\
\hline Out. & 4359,58 & 1800,98 & 0,41 \\
\hline Nov. & 3605,37 & 1877,95 & 0,52 \\
\hline Dez. & 1503,45 & 1426,98 & 0,95 \\
\hline
\end{tabular}

\begin{tabular}{|r|r|}
\hline \multicolumn{1}{|c|}{$\begin{array}{c}\text { Dif } \\
\mathbf{1 4 - 1 3}\end{array}$} & \multicolumn{1}{c|}{$\%$} \\
\hline$-0,03$ & $-2,5 \%$ \\
\hline$-0,03$ & $-2,8 \%$ \\
\hline$-0,06$ & $-5,4 \%$ \\
\hline 0,10 & $6,9 \%$ \\
\hline$-0,03$ & $-1,8 \%$ \\
\hline 0,07 & $4,0 \%$ \\
\hline 0,00 & $-0,1 \%$ \\
\hline 0,04 & $3,0 \%$ \\
\hline$-0,04$ & $-3,1 \%$ \\
\hline$-0,12$ & $-11,4 \%$ \\
\hline$-0,16$ & $-11,8 \%$ \\
\hline 0,26 & $13,9 \%$ \\
\hline & \\
\hline 0,00 & $0,0 \%$ \\
\hline
\end{tabular}

Fonte: Autor

Observa-se que, com as melhorias realizadas, o custo unitário do produto produzido pelos teares 5 e 6 foi reduzido em $R \$ 0,15$ e $R \$ 0,10$ na média anual, respectivamente. Não houve variação média no custo unitário dos produtos produzidos pelo tear 7 , o que ainda pode ser considerado positivo, frente aos problemas já citados anteriormente. Ou seja, apesar da redução na sua produtividade, o custo unitário foi mantido.

\section{CONCLUSÃO}

Este trabalho objetivou aplicar as ferramentas de custeio numa empresa do ramo têxtil, que consistia em implementar o sistema de custeio $A B C$ e determinar se era mais vantajoso fabricar ou terceirizar um determinado tipo de malha. Para isto, foram realizadas melhorias de arranjo físico, a fim de aprimorar o processo de produção e fazer uma justa comparação baseada na estratégia de custeio ABC. 
Custos de produção de artigos têxteis e Avaliação da possibilidade de terceirização da fabricação após a reorganização do arranjo físico Marcelo Aguiar Baptista, Allan Jonathan da Silva, Fabini Hoelz Bargas Alvarez

A situação econômica do país foi um dos fatores que levaram à pesquisa, dado que, na conjuntura atual, onde cada vez mais empresas correm risco iminente de concordatas e falências, é imprescindível o controle de custos e despesas.

A relevância deste trabalho para a empresa será grande. O melhor rastreamento dos custos das atividades ajudará a evitar desperdícios na produção e a tomar decisões com base em dados quantitativos.

Pode-se concluir, com base no método de custeio $A B C$, que, de fato, é economicamente viável produzir internamente ao invés de terceirizar o produto. Frequentemente, com a melhor máquina da fábrica, o custo de se produzir chega à metade do custo de terceirizar. Somente em alguns episódios isolados, o custo de produzir ultrapassa o custo de terceirizar o produto.

O presente trabalho apresenta um estudo prático da aplicação do método $A B C$ numa empresa nacional evisa contribuir com a literatura de gestão de custos, aumentando o grau deconfiança nesta ferramenta.

Propõe-se, para estudos futuros, a exploração dos dados de um período maior de observação para melhor avaliação do comportamento dos custos do tear 7 e a comparação com outras metodologias de custeio.

\section{REFERÊNCIAS}

LIMEIRA, André Luiz Fernandes. (2012). Gestão contábil financeira. (1. ed.). Rio de Janeiro: FGV.

MARTINS, Eliseu. (2010). Contabilidade de custos. (10. ed.). São Paulo: Atlas.

NAKAGAWA, Masayuki. (2001). ABC - custeio baseado em atividades. (2. ed.). São Paulo: Atlas.

PINTO, A. A. G; LIMEIRA, A.L.F; SILVA, C.A.S; COELHO, F.S. (2011). Gestão de custos. (2. ed.). Rio de Janeiro: FGV.

Data de Submissão: 07/03/2016

Data de Aceite: 06/09/2016 